\title{
A Comparative Study of Industrial Tourism of Cities in China
}

\author{
Huimin Wang1, Yunxin Fu² \\ ${ }^{1}$ Jinan University, Guangzhou, China \\ ${ }^{2}$ Department of Tourism Management, School of Management, Jinan University, Guangzhou, China \\ Email: wwwcamellia@163.com
}

How to cite this paper: Wang, H. M., \& Fu, Y. X. (2019). A Comparative Study of Industrial Tourism of Cities in China. Chinese Studies, 8, 13-26.

https://doi.org/10.4236/chnstd.2019.81002

Received: December 27, 2018

Accepted: February 24, 2019

Published: February 27, 2019

Copyright (c) 2019 by author(s) and Scientific Research Publishing Inc. This work is licensed under the Creative Commons Attribution International License (CC BY 4.0).

http://creativecommons.org/licenses/by/4.0/

Open Access

\begin{abstract}
With the increase of people's income and the various demands for leisure, the preference of Chinese travelers has gradually shifted from traditional sightseeing to more distinctive forms of tourism. Industrial tourism, as one of the forms which curious tourists are fond of, has been rapidly developed throughout the country. Cities are the main carriers of industrialization, also are the important places for Industrial tourism. This paper selects Shanghai and Huangshi as sample cities for research, comparing the two cities and showing the difference between the development stages, development types and development models of industrial tourism in the two cities.
\end{abstract}

\section{Keywords}

Industrial Tourism, Industrial Heritage, Company Tours

\section{Introduction}

Industrial tour is memerged in scale at Europe in the 1950s, which was used for big companies to nurture loyal consumers and improve corporate Image. With the upgrading of urban functions and the fading of industrial sites, the protection and redevelopment of industrial sites has also promoted the growth of industrial heritage tourism.

China's industrial tourism rose in the 1990s with a late start. Although the path is not long, domestic industrial tourism resources are abundant. Those resources with added value are easy to tap at the beginning, so it develops rapidly. At present, Domestic industrial tourism has developed into a new stage. According to the statistics of the National Tourism Administration, there were 1157 industrial tourist attractions all over the country by the end of 2016, attracting 428,000 people. In 2017, 140 million tourists visit Industrial sites, and 
the industrial tourism revenue reached 21.3 billion yuan (Fan, 2017). Industrial tourism has become a new bright spot in the development of tourism.

With the transformation of industrialization and the changes in people's tourism demand, industrial tourism has become a hot spot in tourism industry. The competitiveness of industrial tourism has also become a core component of urban competitiveness. At present, the development of industrial tourism in China has local and regional characteristics, mainly concentrated in the four major industrial bases (Shanghai-Nanjing-Hangzhou, Beijing-Tianjin-Tang, south and central of Liaoning province, and Pearl River Delta) and three industrial belts (eastern coastal industrial zone, industrialization zone along the Yangtze River, longhai-Lanxin Industrial Zone), but the concentration has decreased year by year, which is related to the growing number of domestic industrial tourism regions and enterprises (Yang, 2009).

This paper selects two cities, Shanghai and Huangshi, for comparative study. Shanghai is China's most international metropolis with big influence. It is also China's largest industrial center and an important international industrial city with a large amount of industrial resources. Due to the developed economy, good human resources and a relatively mature tourism market, Shanghai's industrial tourism is at the forefront of the country. Located in the central areas of China, Huangshi is a resource-based industrial city with abundant mineral resources and a long industrial history. It is a typical representative of small and medium-sized industrial cities. Shanghai and Huangshi ranked 2nd and 9th in 217 cities on Comprehensive Evaluation of Urban Industrial Tourism (Deng \& $\mathrm{Li}, 2017)$. This shows that the development of industrial tourism in the two cities has its own unique advantages. Shanghai city has abundant achievements in modern industrial period, while Huangshi city has more glorious moments because of the long industrial accumulation. This paper makes comparison between them, who have different city location, scale and type. The purpose is to know the developments of china industrial tourism comprehensively and provide materials and experience for industrial cities which is still looking for the appropriate path. All in all, Shanghai and Huangshi are characterized with their own city quality.

\section{Literature Reviews}

Countries have different history of industrial tourism, also different in the definition of industrial tourism. Most of foreign studies think industrial tourism means "industrial heritage tourism". Sauri-Pujor \& Llurdes-Coit (1995) believes that industrial heritage tourism is a new way of tourism. It is developed from the protection of industrial heritage. It is characterized with sightseeing and leisure by the protecting and transforming machinery, plant buildings in the old industrial site to help visitors know industrial culture and civilization (David \& Joan, 1995). In Chinese literatures, "industrial heritage tourism" and "industrial tourism" are widely used. However, "industrial tourism" mainly refers to "industrial 
production tourism" or "factory sightseeing tourism" (Huang \& Zheng, 2015). Industrial production tourism is the experience of visiting and learning based on the process of industrial production and the culture of industrial enterprises (Wu, 2010). Industrial heritage tourism means the traditional ways of declining industrial areas or cities seeking functional transformation to achieve city regeneration. The definition of industrial tourism used in this paper includes both industrial heritage tourism and industrial production tourism.

The competitiveness of a city is not just about productivity or employment. It should be a multifacted performance indicator. Since 1950, the growing European and American industrial cities have begun to face industrial recession and the city's competitiveness has declined. In order to find new opportunities, some industrial cities in recession view urban marketing as a tool that reshapes the city image to attract investment and tourism (Kavaratzis, 2007). Urban tourism industry takes on some responsibility of urban renewal. The local government capitalizes on local resource to boost city construction and cultural shaping, and attracts enterprises to build city together.

In China, due to the rapid advancement of urbanization, many cities have failed to retain local characteristics during the planning process. The rapid implementation of policies has led to the destruction of industrial buildings. As people's demand for cultural life increases, current urban construction has paid attention to this issue. Industrial heritage tourism is an important tool to improve the region image and offset the public's prejudice against industrial recession (Richards \& Wilson, 2004). Many cities protect and repair the industrial relics. Many cities have assets to develop industrial tourism, but they have not been able to use them. Corporate tours in those cities are limited to low-profile companies with rare publicity. There is no clear strategic vision for developing industrial tourism, not to mention the growth of tourism product. The development of industrial tourism depends to a large extent on the ability of enterprises to cooperate. The ability of enterprises to cooperate depends on the city's economic strength and the potential of industrial tourism (Otgaar et al., 2010). Both industrial heritage and modern companies are important resources for cities. In general, industrial heritage attractions include three sub-categories: industrial museums, industrial heritage sites and creative parks. Modern industrial attractions include company tours, modern industrial museums, and integrated industrial parks (Li, 2002; Yu \& Fang, 2006). Current construction of industrial tourism resources in china is mainly complied with the categorization.

In 1958, the first research conference on urban renewal was held in The Hague, the Netherlands. The concept of urban renewal was defined that it forms a comfortable living environment through urban construction activities. People who live in cities have dissatisfactions and expectations for living environment or living activities hopes to improve housing and environment, as well as promote urban land use (Zhang, 2015). Urban renewal has undergone changes in concepts as an activity to optimizing the urban environment and spatial struc- 
ture. From the rebuilding on a large scale to the small-scale rectification and gradual transformation with people-oriented notion, the connotation of urban renewal is becoming more abundant, which put emphasis on the renewal of culture, ecology and public space. And the process of urban renewal pays more attention to human life and emotional needs. The transformation of industrial space caused by urban renewal provides resources and space carrier for the development of industrial tourism. In response to the policy of the nationwide adjustment on industrial structure, many cities in China have moved factories away from urban centers to develop service industries. These factories moved to the suburbs, occupying large areas of land, where large enterprise bases is located or small and medium-sized enterprises gathered to form industrial parks. And the industrial relics are protected and maintained as public spaces like museums and creative parks, which will increase the leisure options and enhance the public interest. In the formulation of policy and resource utilization, decision makers should consider the characteristics and human factors. The connotation of industrial tourism resources should be explored deeply. Authorities should organize organically industrial tourism in the process of urban function transformation and spatial change, and improve the public involvement in industrial tourism.

\section{Comparison of Two Cities}

\subsection{Industrial Tourism in Shanghai}

Shanghai is an important industrial center city in China. During the industrial development process over 100 years, many well-known industrial enterprises have been born with high reputation. So, the development of industrial tourism has natural advantages. The development of industrial tourism in Shanghai is divided into three stages. In the first stage, the government departments organized the business trips to factories like Baosteel and other state-owned large enterprises. In the second stage, with the diversified development trend of enterprises, many companies have launched more diversified experience tour of industrial production sightseeing, in order to improve their corporate image and market awareness. In the third stage, Shanghai entered the stage of economic development dominated by the service and the knowledge economy. Programs of protection and redevelopment for urban industrial heritage have increased, and industrial tourism and cultural and creative industries actively merged.

At present, Shanghai has 290 industrial heritages, involving 30 manufacturing categories (Shanghai Tourism Administration, 2017). They are mainly distributed along the Huangpu River and the Suzhou River, with a continuous strip-shaped distribution pattern. Most of them are located in the current downtown area of Shanghai. In order to protect the city's industrial heritage and preserve the city's memory, as well as change the functional layout of urban industrial, Shanghai has also transformed some of its old factories and warehouses into creative industrial parks to develop the tertiary industry. This city actively 
introduces capital. With the assistance of government, it combines industrial heritage resources with cultural creativity industries, making it a diversified space for industrial services with comprehensive service functions, and at the same time becoming a carrier for public services. The growth of tertiary industry is rapid, which leads Shanghai's economic development, but industry still occupies an important position. Big enterprises representing modern and advanced technology and a large number of daily consumer products manufacturing enterprises are the basis of Shanghai's industrial production tourism. Currently, the industrial layout of Shanghai is concentrated, and advanced manufacturing industries are gathering in the suburbs. The central city has priority to develop high value-added urban industries and high-end production services.

In 2002, the National Tourism Administration introduced relevant policies that nominated a number of industrial tourism sites as "National Models of Excellence" every year. Companies that become industrial tourism examples can receive additional government support and advocacy. Up to 2018, there were 108 industrial example sites across the country, including 19 in Shanghai. In response to national policies, Shanghai released China's first local industrial tourism development plan, namely "the overall layout of Shanghai s industrial tourism development (2006-2010)”. In 2005, the Shanghai Industrial Tourism Promotion Center (SITPC) was established as a platform organization. In 2018, Shanghai issued the "Three-Year Planning for Industrial Tourism Innovation and Development in Shanghai (2018-2020)", which recommended many industrial attractions and routes. Shanghai will focus on creating five types of industrial tourism products such as industrial heritage, industrial museums, people's livelihood, manufacturing, and major industrial civilization achievements (Shanghai Tourism Administration, 2018).

The SITPC is a non-profit social organization approved by the Shanghai Economic Commission. The Promotion Center develops comprehensive and multi-level strategic cooperation with government agencies, research institutes, industry associations, industrial enterprises, travel agencies and other institutions to explore and integrate Shanghai industrial tourism resources, striving to build professional services for Shanghai's international metropolitan tourism products. The daily expenses of the center and salary of more than 30 employees are provided by the member companies. They rarely rely on government financial allocation. In 2006, SITPC negotiated with well-known industrial enterprises, industrial development zones, creative industry clusters and industrial museums. They integrated nearly 100 industrial tourism sites, designed 11 tourist routes. And a theme activity named "One day Industrial trip in Shanghai" was organized successfully. The details are handled by an affiliated travel agency (Mianyang Tourism Bureau, 2010). At the same time, the Center was commissioned by the Shanghai Tourism Bureau to hold thematic training courses to improve the professional quality and service level of industrial tourism attractions. In recent years, Beijing, Tianjin, Guangdong and other provinces and ci- 
ties have visited Shanghai to study industrial tourism. Some provinces and cities have established an industrial tourism promotion center with reference to the Shanghai model.

Shanghai's industrial tourism products keep innovating and developing, which forms a system of diverse types, covering industrial enterprises, industrial museums, industrial development zones, creative industry clusters, and major engineering construction achievements. More than 100 industrial enterprises, 60 industry museums, over 300 science education bases, nearly 100 cultural creativity industry clusters and more than 60 industrial parks (Chen, 2017), merge the elements of tourism into industry to form a diversified Industrial travel blueprint. At present, there are 19 National Models of Excellence sites in Shanghai, including 4 creative industrial clusters and leisure recreation areas formed on the basis of industrial heritage resources, 11 industrial enterprise attractions, and 4 industrial parks, museums and other industrial tourism products. Among them, the industrial landmark leisure area has the best market response with strong recreation atmosphere and regional appeal. Such as M50, 1933 old workshop, Tianzifang and other scenic spots. Industrial corporations, as the main components of National Models of Excellence sites, attracts tourists. Those include Baosteel Group, Shanghai Tobacco Group Industrial Park, Shanghai Film Studio, Shanghai Geological Museum and other outstanding benchmark companies.

Shanghai mainly promotes three types of theme routes for different groups: The first one is activities designed for the nostalgic elderly; The second one is that Center organizes young students to visit industrial tourism attractions and carry out research-related activities; The third one is to develop business visits and provide travel products for government, business, cooperation and other survey groups. Shanghai has successively launched the "vicissitude of Shanghai-China's industrial visit of discovery", "Speed of Shanghai-China's industry tour", "Sailing in Shanghai-China's shipbuilding industry", and other 75 industrial tourism routes. In 2006, the Shanghai Municipal Tourism Administration cooperated with the District and County Tourism Bureau selected 28 travel agencies as the first batch of industrial tourism units to promote the development of industrial tourism in Shanghai. With the support of all parties, the number of self-developed industrial tourism enterprises has grown from 50 in 2006 to 200 in 2015, and industrial tourism resources have been deeply explored (Lin \& Lin, 2016).

Recently, Shanghai announced the list of excellent and standardized organizations of industrial tourism, respectively 21 and 41 (Shanghai Tourism Administration, 2017). List of 21 organizations with excellent service quality are shown below.

As can be seen from Table 1, there are 8 company tours, 7 creative parks, and 6 museums. Company tours nearly accounts for $40 \%$, indicating that industrial production tourism in Shanghai is developing well. The creative parks are public 
Table 1. Shanghai industrial attractions with excellent service quality.

\begin{tabular}{|c|c|c|c|c|}
\hline Company/Organization & Sector & Scheduled & Price & Group \\
\hline SAIC VOLKSWAGEN & Automotive & Yes & $¥ 50-¥ 60$ & $20-$ \\
\hline BAO STEEL & Steel & Yes & $¥ 40-¥ 60$ & $20-$ \\
\hline GANSO & Dessert & Yes & $¥ 150-¥ 220$ & \\
\hline Peninsula 1919 & Creative Cultural District & No & Optional & \\
\hline BRIDGE 8 & Creative Cultural District & No & $¥ 0$ & \\
\hline Shanghai Railway Museum & Museum & No & $¥ 5-¥ 10$ & \\
\hline HIHGSTREET LOFT & Creative Cultural District & No & $¥ 0$ & \\
\hline Shanghai Textile Museum & Museum & No & $¥ 0$ & \\
\hline MACALLINE & home decoration & No & $¥ 0-¥ 120$ & \\
\hline M50 & Creative Cultural District & No & $¥ 0$ & \\
\hline China Tobacco Museum & Museum & For Group & $¥ 0$ & \\
\hline Shanghai Fashion Center & Creative Cultural District & No & $¥ 0$ & \\
\hline Yakult & Dairy & Yes & $¥ 0$ & $30-50$ \\
\hline TOTOLE & Condiment & Yes & $¥ 0$ & $10-$ \\
\hline Shanghai Auto Museum & Museum & No & $¥ 0-¥ 60$ & \\
\hline Jinlongyu & Edible Oil & Yes & $¥ 0$ & $20-$ \\
\hline China Maritime Museum & Museum & For Group & $¥ 0-¥ 50$ & $16-$ \\
\hline Canature & Environmental Systems & Yes & $¥ 25$ - ¥40 & $10-$ \\
\hline Shanghai Film Park & Theme Park & No & $¥ 25-¥ 80$ & \\
\hline $\begin{array}{c}\text { Shanghai Aviation Science } \\
\text { Museum }\end{array}$ & Museum & No & $¥ 8$ & \\
\hline Yuejie & Creative Cultural District & No & $¥ 0$ & \\
\hline
\end{tabular}

Sources: The author compiled the list according to the information on the official websites.

space that integrates leisure, shopping and cultural experiences by maintaining and updating industrial relics. The museum is either a museum directly related to the original factory site, or a new theme museum nearby. The three categories are the main components of Shanghai's industrial tourism resources, and the quantitative difference is small. This shows that Shanghai's industrial heritage tourism and industrial production tourism development are close, each with its own advantages. Therefore, in the marketing and publicity of urban industrial tourism, Shanghai attaches the same importance to the two types of industrial tourism forms, emphasizing the integration of historical culture and modern technology, presenting the comprehensiveness of an international metropolis.

\subsection{Industrial Tourism in Huangshi}

Unlike Shanghai, Huangshi is a mining city and a pilot city for resource depletion in the country. In 2017, the proportion of the three industries in Huangshi 
was 8.2:57.0:34.8 (Huangshi Statistics Bureau, 2017). It showed that the secondary industry dominated by mining was still the leading industry of Huangshi. However, with the exhaustion of mineral resources, urban development is in recession, and Huangshi is actively seeking opportunities for transformation. Industrial tourism, as an emerging industry that combines elements of travel and industry, provides an opportunity for developing a new way. Rich industrial resources have become the basis for the development of industrial tourism. It can enhance urban infrastructure and improve industrial environment, thus achieving the goal of urban Renewal and industrial upgrading. In 2005, the Ministry of Land and Resources approved the Huangshi National Mine Park as the first batch of national mine parks, which accelerated the protection and redevelopment of industrial heritage in Huangshi. In 2016, there were 100,000 tourists in mine parks, and the income of tourists in the park increased by $20 \%$ every year (Lei, 2017).

The history of mining in Huangshi has lasted over thousand years, leaving many valuable industrial heritages. There are more than 2000 geological relics and mine sites in the city (Lei, 2017). In addition to the historical legacy of profound culture and industrial civilization, New Steel, Nonferrous Metals, Jinpai and other industrial companies are also well-known throughout the country. There are 182 industrial tourism resources in Huangshi, covering two types of modern industrial resources and industrial cultural heritage resources. Among them, there are 27 modern industrial resources and 155 industrial cultural heritage resources (Huangshi Tourism Bureau, 2018). It can be seen that industrial tourism in Huangshi is mainly based on industrial heritage tourism. Huangshi National Mine Park is one of the first 10 national industrial heritage tourism bases. And it is the most popular among all the open industrial tourism sites of Huangshi.

In recent years, this city has compiled "Huangshi overall Protection Planning of Industrial Heritage Area" and "Huangshi Industrial Site Protection Regulations". As the first local industrial heritage regulations in China, the latter provides comprehensive legal protection for industrial heritage and implements projects of environmental renovations. The Huangshi Municipal Business Council (Tourism Bureau) is responsible for tourism related matters, integrating tourism resources of the city. It established investment companies of cultural tourism, strengthening the protection of industrial heritage and promoting the integration of industrial tourism with ecological tourism, sightseeing tours and cultural activities. Huangshi City Industrial Tourism Development Planning (2017-2030) provides detailed procedures for industrial tourism with three phases. The first phase is from 2017 to 2020. It is a three-year action plan for innovation and development industrial tourism in Huangshi, which is the key period of project and brand construction. The second phase is from 2021 to 2025, which is the period of completing function and brand to perfection. The third period is from 2026 to 2030, which is the period of comprehensive improvement and sustainable development of industrial tourism. 
Although there are many geological relics and mine sites in Huangshi, the most representative ones are the four major industrial sites, "the Tonglushan ancient copper mine", "the Daye iron mine", "the Hanye Ping coal mine" and "the Huaxin cement Factory". It is characterized by a long history, complete preservation and good popularity. These four industrial heritages are concentrated in an area of 17 square kilometers, which is conducive to the development of products and route design. Huangshi has initially designed five special industrial tourism routes, "the Journey of Discovering Mining Civilization", "the Journey of popular science of geology and mine", "the Journey of Leisure experience", "the Journey of Mining Industry Research" and "the Journey of metallurgy culture". In addition, there is a tourism project named "Golden Years", which is a small train. This project will connect several major industrial sites. Different themes are designed based on the landscape on both sides of railway. Those themes are garden flowers, industrial memories, bottom of lake and city impression. Transfer station of the line sets at Hanyeping, Xialu, Mine Park, Tonglushan, Huaxin Cement and Huangshi East Station, six stations in total. Each station will be designed by its industrial characteristics and corporate culture. The small train will run 11 laps between the National Day and the Spring Festival of 2019 this year as a pre-trial stage (Huangshi Tourism Bureau, 2018). The market response to these distinctive industrial routes and projects remains to be seen.

It can be found that industrial heritage has been repeatedly mentioned in the image shaping and future planning of Huangshi City. These names have good reputation in China and may have a good brand effect on the development of Huangshi's industrial tourism. The industrial tourism resources of Huangshi City are mainly based on the industrial heritage accumulated by the rich industrial history, so the local government focuses more on industrial heritage tourism in urban marketing and brand positioning.

\section{Conclusion and Discussions}

\subsection{Conclusion}

Shanghai and Huangshi represent the characteristics of industrial tourism in two different types of cities. As a model city, Shanghai has developed economy, complete industrial system and good atmosphere of industrial culture. In 2017, Shanghai's total tourism revenue reached 448.5 billion yuan and received 318 million tourists. The reception number of people in industrial tourism exceeded 13 million (Shanghai Tourism Administration, 2017). This indicates that Shanghai industrial tourism has broad market prospects. Huangshi is a typical example of small and medium-sized industrial cities. Its resources are exhausted and the city needs new blood. In Huangshi, urban industrial atmosphere is strong. Infrastructure conditions are not good and the urban environment needs to be improved. In 2017, Huangshi's total tourism revenue was 14.12 billion yuan, receiving 22.203 million tourists (Huangshi Statistics Bureau, 2017). As a small and medium-sized city in inland regions, Huangshi can attract tourists from the 
local and surrounding cities, which is the basis for the development of local industrial tourism. The following conclusions can be drawn from the perspectives of the industrial tourism resources, utilization and image positioning of the two cities.

First of all, the development phases of industrial tourism in the two cities are different. Industrial tourism in Shanghai is in the middle phase. The industrial resource has been developed into multiple tourism types. Now, Shanghai pays more attention to experience programs and interaction with tourists. The number of tourists has already reached a big scale. The increasingly diversified industrial tourism projects have also attracted more groups. At the same time, the industry organizations are functioning well in Shanghai. They have accumulated experience in promotion, organizing activities, connecting tourists and relationships with enterprises and the government. The industrial tourism in Huangshi City is still in the preliminary phase. The market is still dominated by traditional "sightseeing tours", lacking in cultural connotation and participation. It is a little bit far from the demands tourism market. Visitors mainly come from the cities and counties of this region and a small number of people from the neighboring cities. The number of tourists in Huangshi does not reach a big scale. In addition, travel agencies are in level of low involvement, and market information is relatively lag. At present, most industrial sites have not been exploited, and the open industrial attractions focus on exhibiting photos, words and things, lacking in projects with high-interaction.

Secondly, the types of industrial tourism development in the two cities are different. Industrial heritage tourism and industrial production tourism in Shanghai have similar importance and attention. There are kinds of industrial tourism companies got involved in the new industry because industrial system is complete and, ranging from light manufacturing like food, brewing, and handicraft enterprises to heavy industries like Baosteel and Volkswagen Group. Moreover, many high-tech industries have gradually joined. The transformation of the industrial heritage project has now achieved some results and has become a landmark for tourists. The form of industrial tourism in Huangshi is dominated by industrial heritage tourism because the industrial structure of Huangshi is relatively single compared with Shanghai. There are many traditional heavy industry enterprises related to minerals. The relics left by the heavy industries in Huangshi are numerous. So, the resources of industrial heritages are more abundant. Industrial heritage tourism focuses on the urban economy and facilitates urban renewal, while industrial production tourism is pay more attention to corporate development. Nowadays, there are few industrial enterprises involved in industrial tourism in Huangshi and their tourism services function is not qualified.

Finally, the directions of industrial tourism in the two cities are moving differently. Shanghai's goal is to build a world-famous tourist city with global influence and improve the tourism industry system. According to the 'Thirteenth 
Five-Year Plan' of Shanghai's tourism reform and development, Shanghai will pay more attention to cultivating urban high-quality cultural leisure and holiday service functions. Therefore, the direction of industrial tourism in Shanghai should be in line with its development goals and become part of its tourism landscape system. At present, the transformation of Shanghai's industrial relics is mainly transformed into creative industrial parks, public recreation spaces and theme museums. The goal of Huangshi is to become an important key city along the Yangtze River and a regional tourism center city in eastern Hubei based on the regional market. Although industrial tourism in Huangshi is in its infancy, the development model adopts the regional integration model. It regards the industrial resources within the entire city as a whole, and carries out comprehensive remediation plans to become an industrial tourism city. This development model will help the entire region to plan together and form a brand awareness, which can improve the level of urban industrial tourism (Table 2).

\subsection{Discussions}

Although there are differences between two cities, but they also have some problems in common. Things like product portfolio, marketing, transportation, public service support still need to be improved. Due to huge urban system of Shanghai, various forms of tourism such as urban sightseeing, cultural tourism, eco-tourism, and event tourism have developed rapidly. For industrial tourism, only by finding its own characteristics and scaling up can it gradually occupy more shares in the tourism market. In this regard, Shanghai can learn from Taiwan's experience. As an international metropolis, tourism has always been a pillar industry. Diverse forms of tourism and fabulous experiences have become an indispensable part of Taiwan tourism. Industrial tourism has also brought considerable benefits to Taiwan. Taiwan combines industrial heritage with hot spring and home stays to bring new vitality. Shanghai can also combine industrial heritage with other forms of tourism that have advantages in the market, so that the pattern of protection and reuse of industrial heritage can be various. Industrial production tourism also has successful experience in Taiwan. The Industrial Bureau of the Ministry of Economic Affairs of Taiwan promulgated the "Operation of Factory with Sightseeing Service Operations" in 2003. The factory tour in Taiwan means that a factory or workshop show their production, manufacturing process, and plant to visitors and offer experience services for tourists.

Table 2. The comparative contents of two cities.

\begin{tabular}{ccc}
\hline Comparative Items & Shanghai & Huangshi \\
\hline Development Phase & Middle & Preliminary \\
Development Type & $\begin{array}{c}\text { Industrial heritage tourism and } \\
\text { industrial production tourism are of } \\
\text { equal importance }\end{array}$ & $\begin{array}{c}\text { Dominated by Industrial } \\
\text { heritage tourism }\end{array}$ \\
Development Direction & World-famous tourist city & Regional tourism center city \\
\hline
\end{tabular}


Those factories are actually engaged in manufacturing and processing, possessing the value of sightseeing, education and industrial culture (Zhang, 2015). Up to 2017, there are 133 companies participating in "Factory Tours" in Taiwan. In 2016, the number of visitors reached 22.1 million. The total revenue of manufacturers from tours in 2016 was NT\$4.6 billion (Ren, 2017). The Taiwan Tourism Factory is market-oriented, focusing on tourism needs. It has developed a wide range of unique creative products. Among them, companies that produce daily necessities such as foods pay particular attention to the tourism market. Companies in mainland China mainly stay at the stage of popularizing knowledge and factory display, lacking in experience and attraction.

Huangshi can learn from the Ruhrgebiet in Germany. Both of them have a long history of heavy industries and many industrial relics. Huangshi was relatively late to develop industrial tourism. Many industrial resources are at undeveloped stage or the initial development stage. This will facilitate the overall planning of resources in the future and create brands to attract customers, thereby gaining profits and expanding urban influence in the regional market. In 1998, the industrial tourism in the Ruhrgebiet began integrating, including unified marketing, scenic spot planning and product mix. In order to create a classic route, the relevant department have integrated the main industrial attractions of this region into the famous "Route Industrial", which includes 19 industrial attractions, 6 national industrial museum of technologies and social history, 12 typical industrial settlements, and nine watchtowers converted from abandoned industrial facilities. In addition, 25 special tourist routes covering 500 scenic spots covering the entire Ruhrgebiet were designed. The Ruhrgebiet has designed the color of visual symbol, the description card and the signboard (Liu \& $\mathrm{Li}, 2004)$. Current industrial product planning in Huangshi has similarities with the Ruhrgebiet. Huangshi can learn the successful experience from management and branding of Ruhrgebiet.

The process of urban renewal and design of the two cities have affected the development of industrial tourism. Shanghai and Huangshi will promote the development of industrial tourism according to their respective positions. They can learn from other regions and integrate local resources to create a prospective market.

At present, there are not many comparative studies on china industrial tourism cities. This paper compares the two cities with different attributes and draws conclusions about their respective development stages, development types and future development models, showing the advantages and disadvantages of the cities. And this paper combines the characteristics of the two cities, and then puts forward relevant suggestions. Other cities are able to find the positioning and experience that suits them through the experience of these two cities. In addition, this article provides substantial material for future china industrial tourism research. In the future, the author will research this topic through more detailed data. 


\section{Conflicts of Interest}

The authors declare no conflicts of interest regarding the publication of this paper.

\section{References}

Chen, A. P. (2017). China Industrial Tourism Enters into a Golden Time. http://www.xinhuanet.com/2017-01/31/c_1120396858.htm

Deng, H. B., \& Li, J. M. (2017). China Development Report of Industrial Tourism. Huangshi: China University Geosciences.

Fan, H. T. (2017). Industrial Tourism Received 1.4 Billion Tourists. http://travel.people.com.cn/n1/2017/1129/c41570-29673478.html

Huang, L., \& Zheng, Y. (2015). Reviews on Tourism Development of Resources-Based Cities. Resources \& Industries, 5, 14-21.

Huangshi Statistics Bureau (2017). Huangshi Statistical Bulletin in 2017. http://www.huangshi.gov.cn/zwgk/tjxx/201808/t20180817_511769.html

Huangshi Tourism Bureau (2018). Huangshi Industrial Tourism Development Plan (20172030). http://www.hsdcw.com/html/2018-7-3/923482.htm

Kavaratzis, M. (2007). City Marketing: The Past, the Present and Some Unresolved Issues. Geography Compass, 1, 695-712. https://doi.org/10.1111/j.1749-8198.2007.00034.x

Lei, Y. (2017). Huangshi Transformation for Treatment of Drawbacks: Big Mining Pit Change into $4 A$ Scenic Spot. http://www.dzwww.com/xinwen/shehuixinwen/201711/t20171127_16710793.htm

Li, L. (2002). De-Industrialization and Development of Industrial Heritage Tourism: The Actual Process and Development Model of Ruhr in Germany. World Regional Studies, 11, 57-65.

Lin, Z., \& Lin, L. Q. (2016). Shanghai Practice of Industrial Tourism Development. http://www.toptour.cn/tab1648/info232094.htm

Liu, H. Y., \& Li, L. L. (2004). An Observation on German Industrial Tourism. Urban Research, 9, 15-21.

Mianyang Tourism Bureau (2010). Mechanism Innovation of Shanghai Industrial Tourism. http://www.mysta.gov.cn/lyxw/yjzt/system/2008/08/4/000047187.html

Otgaar, A. H. J., van den Berg, L., \& Feng, R. X. (2010). Industrial Tourism Opportunities for City and Enterprise. Routledge.

Ren, C. Q. (2017). The Secrets of "Factory Tour" in Taiwan. http://paper.people.com.cn/rmrbhwb/html/2017-04/28/content_1770247.htm

Richards, G., \& Wilson, J. (2004). The Impact of Cultural Events on City Image: Rotterdam, Cultural Capital of Europe 2001. Urban Studies, 41, 1931-1951. https://doi.org/10.1080/0042098042000256323

Sauri-Pujor, D., \& Llurdes-Coit, J. C. (1995). Embellishing Nature: The Case of the Salt Mountain Project of Cardona Catalonia, Spain. Geoforum, 1, 35-48.

https://doi.org/10.1016/0016-7185(95)00016-E

Shanghai Tourism Administration (2017). http://lyw.sh.gov.cn/lyj_website/HTML/DefaultSite/portal/index/index.htm

Shanghai Tourism Administration (2018). http://lyw.sh.gov.cn/lyj_website/HTML/DefaultSite/portal/index/index.htm

Wu, H. (2010). Mode and Enlightenment of Ruhr District Industrial Heritage Tour in 
Germany. Journal of Taiyuan University, 3, 77-79.

Yang, Z. (2009). Development Characteristics and Organization Optimization of China's Industrial Tourism Industry. Journal of Shandong Agricultural University (Social Science Edition), 84-95.

Yu, K., \& Fang, W. (2006). Exploring China's Industrial Heritages. Architectural Journal, No. 8, 12-15.

Zhang, L. (2015). A Study on the Organic Combination Model of Taiwan's Leisure Agriculture and Tourism Factory. Northern Economy and Trade, 8, 309-310.

Zhang, Q. (2015). The Theory of Urban Regeneration about Times Space Degree. Xiamen: Xiamen University Press. 